\title{
Conference on ICDP's New Science Plan
}

by Ulrich Harms and Thomas Wiersberg

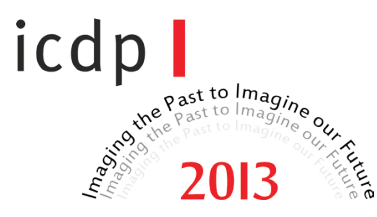

The Earth science community is invited to take part in the development of the International Continental Scientific Drilling Program's new Science Plan by contributing to the conference "Imaging the Past to Imagine our Future", to be held 11-14 November 2013 in Potsdam, Germany.

Over the past fifteen years the International Continental Scientific Drilling Program (ICDP) has served the scientific community through financial and operational support for high-profile international drilling projects. ICDP projects have significantly contributed to major advances in understanding Earth's cycles, structure, and evolution including its environment and life. Since 2005, sixteen drilling projects have been conducted, and more than thirty workshops were held with ICDP support under the umbrella of ICDP's current Science Plan (Fig. 1).

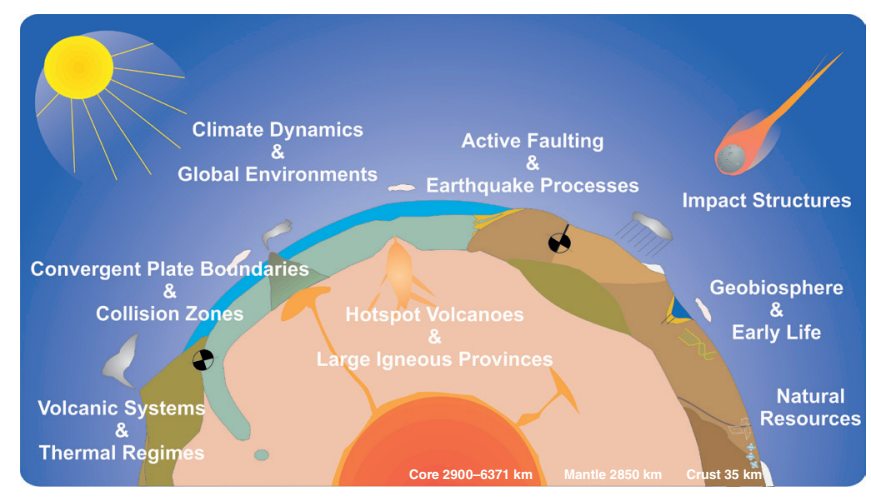

Figure 1. Summary of key themes of the ICDP since the year 2005

The ICDP conference in November 2013 will define the new Science Plan, and it will be structured to link the themes shown in Figure 1 into two major categories: Understanding of Geoprocesses and Societal Challenges. The former includes faulting and earthquake processes, heat and mass transfer, global cycles, and the hidden biosphere; the latter theme involves topics such as water quality and availability, climate and ecosystem evolution, energy and mineral resources, and natural hazards. This matrix format of the meeting is illustrated in Fig. 2.

The conference will start with keynote talks on ICDP's achievements and present scientific projects, followed by discussions of the four subtopics in Understanding of

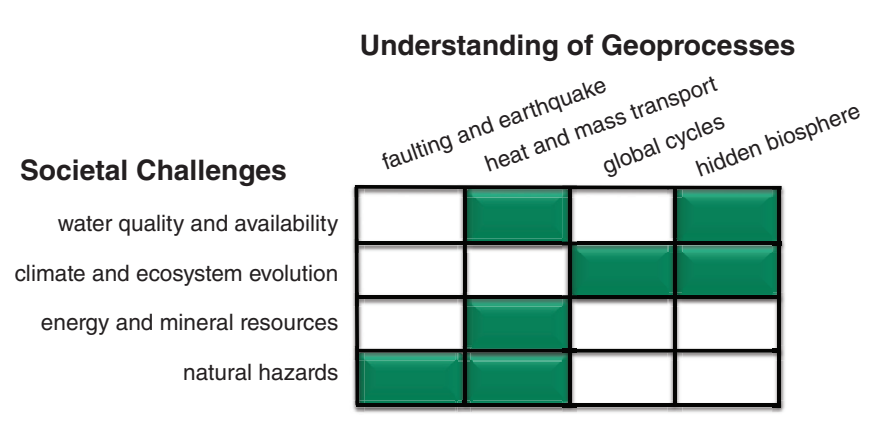

Figure 2. Matrix structure for ICDP's new science plan showing in green where Societal Challenges topics meet the themes of Understanding of Geoprocesses.

Geoprocesses each in plenary half-day sessions including perspectives on how societal and economic criteria apply. Further topics addressed in separate sessions will be Technology at Work (drilling, logging, monitoring), Industry Perspectives of Scientific Drilling, and Information Transfer and Outreach.

"Imaging the Past to Imagine our Future" will bring together scientists, ICDP stakeholders, media representatives, policymakers, and industry professionals. The number of conference attendees is limited, but keynote talks, discussions, and the planned media conference can be followed worldwide via live video webcasts including interactive capabilities through the ICDP Web site.

The conference will produce a white paper explaining the new ICDP Science Plan to stakeholders, funding organizations, politicians, and decision makers, as well as serving the science community as a guideline for developing ICDP proposals. In addition, a special issue of a scientific journal will address overviews of the state of the art and highlight the scientific achievements of ICDP over past years.

Details of the conference are explained at www.icdponline.org/conference 2013

\section{Authors}

Ulrich Harms, and Thomas Wiersberg, German Research Centre for Geosciences GFZ, Potsdam, e-mail: ulrich. harms@gfz-potsdam.de 